\title{
A comparison of mesopic visual acuity and objective visual quality following cataract surgery with hydrophobic acrylic intraocular lenses
}

This article was published in the following Dove Press journal:

Clinical Ophthalmology

7 April 2017

Number of times this article has been viewed

\author{
George HH Beiko ${ }^{1,2}$ \\ Miso Gostimir ${ }^{3}$ \\ Lila Haj-Ahmad ${ }^{4}$ \\ 'University of Toronto, Toronto, \\ 2 McMaster University, Hamilton, \\ ${ }^{3}$ Ottawa University Medical School, \\ Ottawa University, Ottawa, ON, \\ ${ }^{4}$ McGill University Medical School, \\ McGill University, Montreal, \\ QC, Canada
}

Purpose: To evaluate mesopic visual acuity and visual quality as measured by objective scatter index (OSI) in pseudophakic eyes with long-term follow-up after implantation of hydrophobic acrylic lenses made from two different lens materials.

Setting: This study was carried out in a private clinic.

Design: This study was an observational cohort study.

Methods: This pilot study included 181 eyes of 136 patients who had undergone cataract surgery with implantation of monofocal hydrophobic acrylic intraocular lenses (IOLs), either Alcon AcrySof ( 82 eyes) or Abbott Medical Optics' Tecnis ( 99 eyes). The monocular corrected distance visual acuity (CDVA) of the subjects was recorded under mesopic room illumination and OSI was measured by an optical quality analysis system using double-pass wavefront method.

Results: Mean follow-up duration was $60.07 \pm 18.82$ months. Eyes implanted with Tecnis IOLs had statistically significantly better mesopic CDVA $(0.08 \pm 0.08)$ compared to those implanted with AcrySof IOLs $(0.11 \pm 0.07)(P=0.020)$. Mesopic CDVA of $20 / 25$ or better was found in $79.8 \%$ of eyes in the Tecnis group compared to $62.2 \%$ of eyes in AcrySof group. Similarly, OSI was also found to be statistically significantly better for Tecnis IOLs compared to AcrySof IOL group (mean OSI, Tecnis: 1.65 \pm 0.92 , AcrySof: $2.01 \pm 1.36 ; P=0.033$ ). When glaucomatous eyes were excluded, OSI was still significantly better $(P=0.028)$ in the Tecnis IOL group.

Conclusion: The eyes implanted with Tecnis IOLs showed better long-term optical performance in terms of both OSI and mesopic visual acuity in comparison to those with AcrySof IOLs.

Keywords: objective scatter index, double pass, optical quality analysis system, optical performance of IOL

\section{Introduction}

Quality of vision is dependent upon a number of factors, including defocus, the presence of optical aberrations, and the degree of light scatter. ${ }^{1-3}$ Light entering the eye scatters as a result of optical imperfections. ${ }^{4}$ This scattering of light in eyes can occur in backward or forward directions. Light scattered from a surface inside the eye (eg, intraocular lenses [IOLs]) back toward the external light source (backward light scatter) can be observed at the slit lamp. ${ }^{5}$ Forward light scatter (also called intraocular scatter or retinal stray light) is composed of the light scattered toward the retina ${ }^{5}$ and may be quite noticeable to the patient, even though it cannot be directly visualized by an external observer. Optical modeling suggests that forward light scatter severely degrades retinal image quality, ${ }^{1,5}$ potentially reducing visual acuity, impairing contrast, and inducing glare. ${ }^{5}$ The literature on the clinical impact of forward light scatter is limited, due to the inability to objectively measure light scatter clinically in the past.
Correspondence: George HH Beiko 180 Vine Street, Suite 103, Niagara Health Centre, St Catharines, ON L2R 7P3, Canada Tel +l 9057086479 Email georgebeiko@hotmail.com $\mathrm{BY}$
hC for commercial use of this work, please see paragraphs 4.2 and 5 of our Terms (https://www.dovepress.com/terms.php). 
Recently, an objective and quantitative double-pass wavefront device has been used to analyze light scatter in the eye. ${ }^{6}$ It has been fully described elsewhere. ${ }^{3,5}$ Briefly, an infrared video camera records an image of a point source of light that has been projected onto the retina and reflected back in a "double pass" through the ocular media. The ratio of light recorded in peripheral or eccentric areas of the point spread function to that recorded in the central 1 minute of arc is reported as the objective scatter index (OSI). ${ }^{2}$ The higher the OSI, the greater the level of intraocular light scatter.

Light scatter may be caused by a poor quality or rapidly breaking tear film, ${ }^{7,8}$ lens opacity, microvacuoles, or material defects in an implanted lens, posterior capsular opacification (PCO), vitreous floaters, and other factors. ${ }^{9}$ There is a positive correlation between OSI and total ocular aberrations, ${ }^{2}$ although it is not clear whether spherical aberration by itself has any significant impact on OSI.

The literature on OSI in pseudophakic eyes is limited and the contributions of lens material and design features have not yet been well characterized. Nanavaty et al found comparatively higher mean OSI for hydrophilic (2.2-2.7) vs hydrophobic acrylic IOLs (1.6-1.8) 3 months postoperatively. ${ }^{10}$ Higher OSI values have been observed for multifocal IOLs ${ }^{1,3}$ than for monofocal IOLs of the same material. ${ }^{2}$

This pilot study was undertaken to better characterize mesopic visual acuity and visual quality, as measured by OSI, in pseudophakic eyes with long-term follow-up after implantation of hydrophobic acrylic lenses made from two different lens materials.

\section{Methods}

This observational cohort study included subjects who had undergone cataract surgery previously with implantation of monofocal IOLs made from one of two different hydrophobic acrylic materials: with either AcrySof (SA60; Alcon Laboratories, Inc., Fort Worth, TX, USA) or Tecnis (ZCB00; Abbott Medical Optics Inc., Santa Ana, CA, USA) IOLs. Data were collected between June and July 2015. The study protocol adhered to the tenets of the Declaration of Helsinki and was approved by an Institutional Review Board, the Research Ethics Board of the Niagara Health System, St Catharines, Canada (REB Project \# 2015-06-001).

Inclusion criteria included normal pseudophakic eyes as determined by an ophthalmic examination, astigmatism $<1.50 \mathrm{D}$, postoperative corrected distance visual acuity (CDVA) of 6/12 or better, a well-positioned IOL postoperatively, absence of PCO in the central $4.0 \mathrm{~mm}$ of the optic, no intraoperative or postoperative complications, and follow-up of at least 1 year. Patients with a previous history of ocular or intraocular surgery, evidence of trauma, amblyopia, opacity of ocular media (corneal, posterior capsular, or vitreous), corneal surface problems including dry eye, spherical equivalent greater than $1.00 \mathrm{D}$ or astigmatism higher than $1.50 \mathrm{D}$, retinal disease, glaucoma with significant visual field loss, or IOL decentration of more than $0.5 \mathrm{~mm}$ were excluded from this study.

Patient records were reviewed for candidates who would meet the inclusion criteria and these patients were invited to visit the clinic for participation in the study. Patients seen in clinic who met the inclusion criteria were also invited to participate in the study. The study was explained to the patients and written informed consent to participate was obtained. The monocular CDVA of the patients was tested using Snellen visual acuity charts at $6 \mathrm{~m}$ under mesopic room illumination and OSI was measured by an optical quality analysis system using double-pass wavefront method (AcuTarget HD; Visiometrics SL, Terrassa, Spain).

Subjects were asked to focus on the OQAS (optical quality analysis system) analyzer target and to maintain a normal blink frequency. Objective refraction was measured at a pupil diameter setting of $4 \mathrm{~mm}$. Next, two OSI measurements were taken and averaged. If the difference in the two measurements was large, a third measurement was taken and the average of the two measurements that were closest in value was recorded. Tear film analysis, in which OSI is measured every 0.5 seconds for 20 seconds, was also performed. Patients with suspected tear deficiency, as defined by Tutt et al, ${ }^{8}$ were excluded.

\section{Statistical analysis}

Statistical analysis of the data was carried out with Statistical Package for the Social Sciences (SPSS) software (Version 17.0; SPSS Inc., Chicago, IL, USA). The Shapiro Wilk test and Q-Q plots were used to check the normality of the data. To compare outcomes between the two groups, independent $t$-test was used to compare the scale data; the differences in the demographic variables were evaluated using chi-square test. The differences were considered statistically significant when the $P$-value was $\leq 0.05$. Analyses were performed for all eyes and for non-glaucomatous eyes. Scatter plot analysis was used to find the correlation between OSI and postoperative follow-up duration. Correlations were evaluated using Pearson correlation coefficient.

\section{Results}

This retrospective pilot study included 226 eyes, of which 45 eyes were excluded due to poor tear film. A total of 181 eyes of 136 patients were considered acceptable for final 
Table I Patient demographic data for Alcon AcrySof $(n=82)$ and AMO Tecnis group $(n=99)$

\begin{tabular}{|c|c|c|c|}
\hline Variables & Alcon AcrySof & AMO Tecnis & $P$-value \\
\hline Age (mean $\pm S D)$ & $77.8 \pm 7.5$ & $74.8 \pm 9.4$ & $0.020 *$ \\
\hline$\%$ males & 46.34 & 43.43 & $0.695^{\#}$ \\
\hline$\%$ females & 53.66 & 56.57 & \\
\hline$\%$ diabetes mellitus & 20.73 & 15.15 & $0.327^{\#}$ \\
\hline$\%$ glaucoma & 39.02 & 13.13 & $0.000^{\#}$ \\
\hline$\%$ Nd:YAG laser capsulotomy & 36.59 & 42.42 & $0.424^{\#}$ \\
\hline IOL power (mean \pm SD) & $21.4 I \pm 2.53$ & $21.08 \pm 3.99$ & $0.521 *$ \\
\hline Follow-up (months) & $57.09 \pm 20.50$ & $62.51 \pm 17.05$ & $0.054 *$ \\
\hline
\end{tabular}

Notes: $*$ Independent $t$-test $P$-value; ${ }^{\#}$ chi-square test $P$-value.

Abbreviations: SD, standard deviation; IOL, intraocular lens; AMO, Abbott Medical Optics; Nd:YAG, neodymium-doped yttrium aluminum garnet laser.

analysis. Table 1 shows the demographic and clinical profile of the study population. Of the 181 eyes, 82 were implanted with Alcon AcrySof IOLs (SN60WF or SN60AT models) and 99 eyes were implanted with AMO (Abbott Medical Optics) Tecnis (ZCB00) IOLs. Mean follow-up for all eyes was 5 years $(60.07 \pm 18.82$ months $)$.

The two groups were comparable in gender, IOL power, the number of patients affected by diabetes mellitus (controlled and not associated with any visual loss), and incidence of neodymium-doped yttrium aluminum garnet laser capsulotomy. There was a statistically significant difference in mean age $(P=0.020)$ and the number of patients affected by glaucoma (without visual field loss) $(P<0.001)$. The duration of follow-up was longer in the Tecnis eyes, but this did not reach significance $(P=0.054$; Table 1$)$.

Mesopic visual acuity and OSI results by IOL type are shown for all eyes (Figures 1 and 2) and for non-glaucomatous

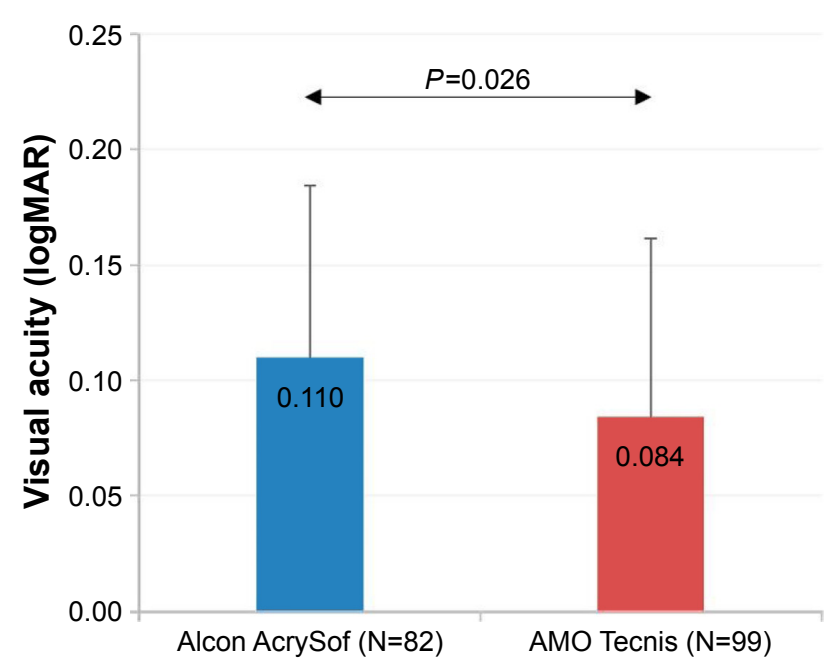

Figure I Comparison of postoperative mesopic CDVA (all eyes). Mean CDVA was significantly better in the eyes implanted with Tecnis IOLs $(P=0.026)$ (error bars represent standard deviation).

Abbreviations: AMO, Abbott Medical Optics; CDVA, corrected distance visual acuity; IOLs, intraocular lenses.

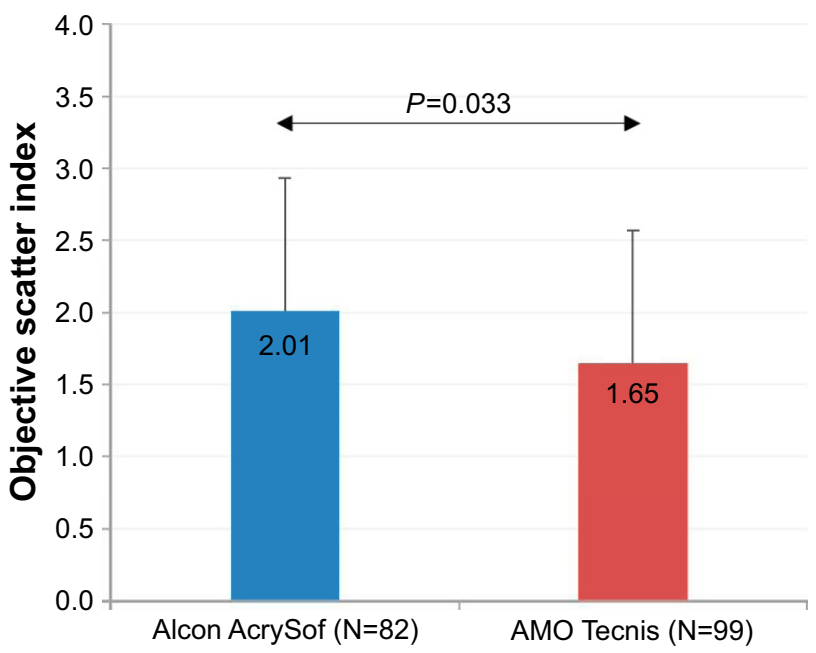

Figure 2 Comparison of postoperative OSI values (all eyes). There is a statistically significant difference between the two groups in mean OSI value $(P=0.033)$ (error bars represent standard deviation).

Abbreviations: AMO, Abbott Medical Optics; OSI, objective scatter index.

eyes only (Figures 3 and 4). The Tecnis eyes had statistically significantly better mesopic CDVA $(P=0.020)$ and OSI $(P=0.033)$ in all eyes and significantly better OSI in nonglaucomatous eyes.

Postoperatively, mesopic CDVA of 20/25 or a better CDVA was found in $79.8 \%$ of eyes in the Tecnis group compared to $62.2 \%$ of eyes in the AcrySof group (Figure 5). A larger percentage of eyes showed $20 / 25$ or better CDVA in the non-glaucomatous subgroup, as well (Figure 6).

In a scatter plot of OSI values by duration of postoperative follow-up, there is a slight trend toward increasing OSI

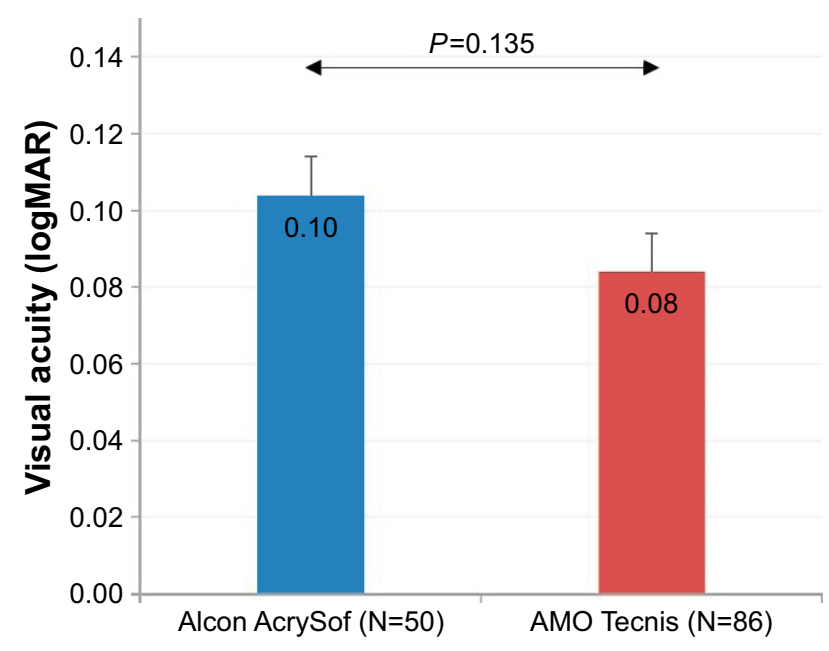

Figure 3 Comparison of postoperative mesopic CDVA in the non-glaucomatous eyes. Mean mesopic CDVA was better in the non-glaucomatous eyes implanted with Tecnis IOLs, although the difference was not statistically significant $(P=0.135)$ (error bars represent standard deviation).

Abbreviations: AMO, Abbott Medical Optics; CDVA, corrected distance visual acuity; IOLs, intraocular lenses. 


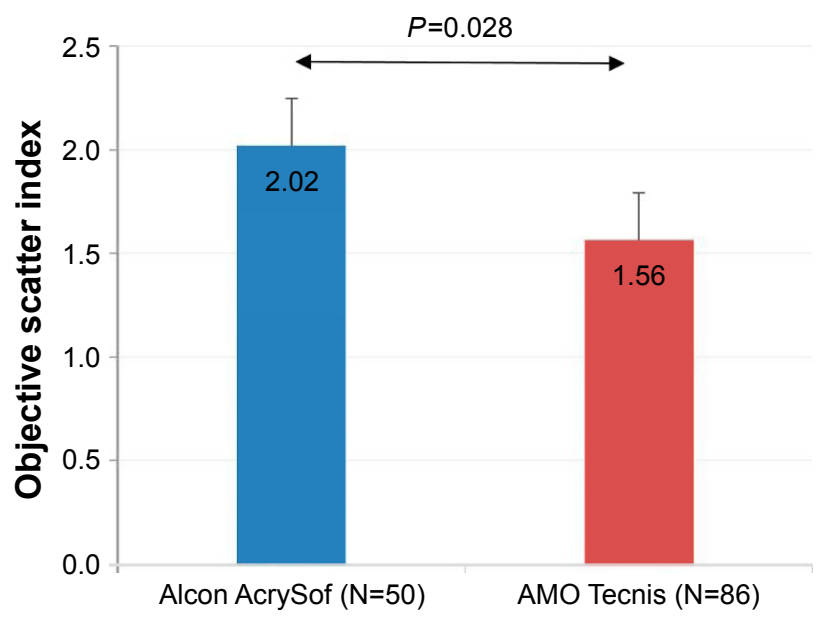

Figure 4 Comparison of postoperative OSI values in the non-glaucomatous eyes. Mean OSI was statistically significantly higher in non-glaucomatous eyes implanted with AcrySof IOLs ( $P=0.028)$ (error bars represent standard deviation).

Abbreviations: AMO, Abbott Medical Optics; OSI, objective scatter index; IOLs, intraocular lenses.

among AcrySof eyes $(r=0.064 ; P=0.572)$ and decreasing OSI among Tecnis eyes $(r=-0.020 ; P=0.857$ ) (Figure 7).

\section{Discussion}

The optical quality of the phakic eye depends on defocus, light scattering, and optical aberrations. After cataract surgery, the optical quality of the pseudophakic eye is influenced by aberrations and light scattering induced by the IOL. ${ }^{1}$ In the present study, we assessed the impact of two hydrophobic acrylic IOL materials (Alcon AcrySof and AMO Tecnis) on mesopic visual acuity and quality of vision several years after implantation.

We used double-pass wavefront technology to measure forward light scatter on an OSI. The OSI shows the degree of objective scattering caused by the loss of ocular transparency. ${ }^{11}$ Normal OSI values in healthy eyes have been documented to be lower than $1.0 .{ }^{12}$ In the present study, we found the mean OSI measurements to be higher than 1.0 in

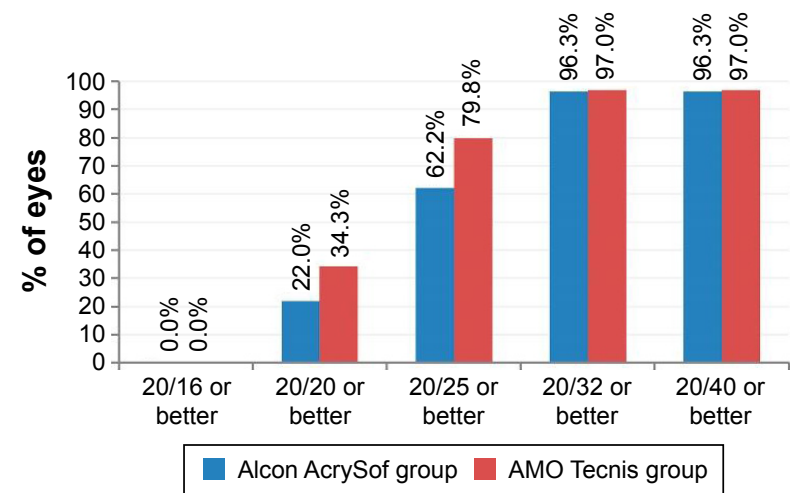

Figure 5 Distribution of postoperative mesopic CDVA by IOL group (all eyes). Abbreviations: AMO, Abbott Medical Optics; CDVA, corrected distance visual acuity; IOL, intraocular lens.

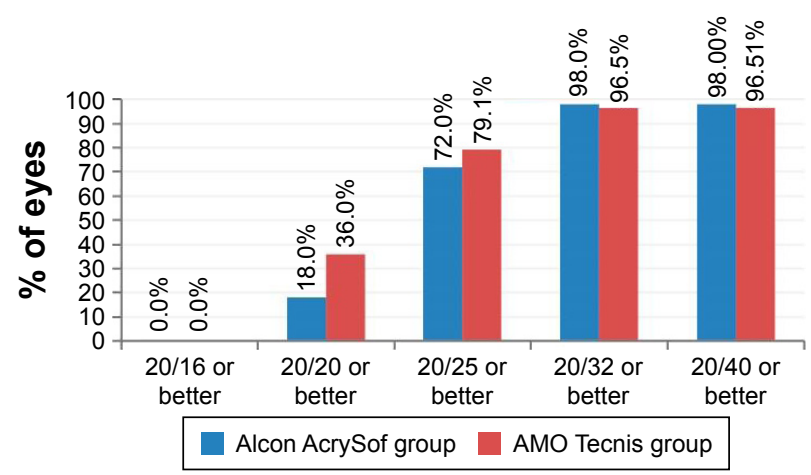

Figure 6 Distribution of postoperative mesopic CDVA by IOL group (nonglaucomatous eyes only).

Abbreviations: AMO, Abbott Medical Optics; CDVA, corrected distance visual acuity; IOL, intraocular lens.

both IOL groups, with a statistically significant difference between the Tecnis IOL group (1.65 \pm 0.92$)$ and the AcrySof IOL group $(2.01 \pm 1.36)(P=0.033)$.

The expected early postoperative OSI in pseudophakic eyes implanted with monofocal Tecnis lenses has not been studied. Several studies have previously documented mean OSI with monofocal AcrySof IOLs at different postoperative follow-up periods, ranging from 1.38 at 3 months to 1.8 at nearly 1 year postoperatively., ${ }^{2,5,10}$ In the current study, the OSI values for eyes implanted with monofocal AcrySof IOLs were higher than previously reported: 2.01 at a mean of 57 months, with some patients followed for up to 10 years. While the OSI reported in diverse settings across different

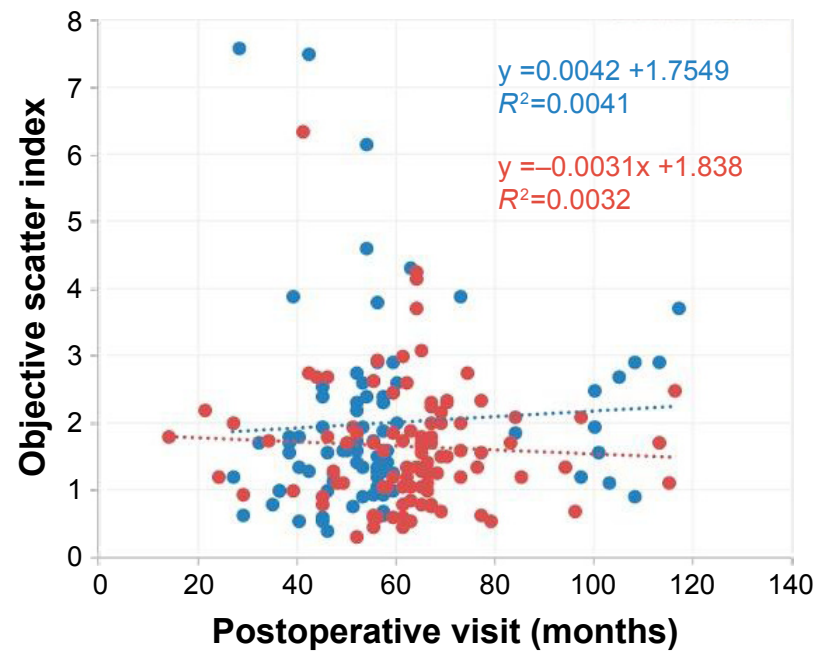

$\begin{array}{lll}\text { - Alcon AcrySof } & \text {-...-...... Linear (Alcon AcrySof) } \\ \text { - AMO Tecnis } & \text {-...-...... Linear (AMO Tecnis) }\end{array}$

Figure 7 A scatter plot showing the correlation of OSI with duration of postoperative follow-up (months) in all eyes of both IOL groups. There is a positive trend (increasing OSI over time) among AcrySof eyes (blue) and a negative trend among Tecnis eyes (red).

Abbreviations: AMO, Abbott Medical Optics; OSI, objective scatter index; IOL, intraocular lens. 
studies demonstrates an upward trend (suggesting a decline in the quality of vision with longer duration of implantation in AcrySof-implanted eyes), the correlation between OSI and duration of implantation in the current study data was found to be weak ( $r=0.064 ; P=0.572$ for AcrySof and $r=-0.020$; $P=0.857$ for Tecnis) (Figure 7) and not statistically significant. Future larger studies may confirm the trend observed in the current study. Patients implanted with these lenses have previously been shown to be more likely to modify their driving habits (reducing speed, distance traveled, and nighttime driving) and to report more road-traffic accidents 2-3 years after implantation, which may also be indicators of decreased visual quality, possibly due to light scatterinducing disability glare, over time. ${ }^{9}$

Differences in the optical performance of the IOLs in the current study, which have similar optical design features, may be attributable to the development of glistenings in the AcrySof IOLs. Although the rate of glistenings was not evaluated in the present study, the literature strongly suggests that glistenings are likely to be present in the majority of AcrySof IOLs, ${ }^{13,14}$ that the rate of glistenings in these IOLs significantly exceeds that of other hydrophobic acrylic IOLs ${ }^{14-16}$ and that both the size and density of glistenings worsen over time. ${ }^{15}$

Glistenings may contribute to poor optical quality. ${ }^{17}$ Nagata et al analyzed eyes implanted with spherical AcrySof IOLs, aspheric Tecnis IOLs, or spheric Hoya hydrophobic acrylic IOLs at 1 week, 6 months, and 1 year after implantation and found statistically significant increases in light scatter in the AcrySof and Hoya eyes over time, but not in the Tecnis eyes. ${ }^{18}$ Another study showed that surface (backward) light scattering with AcrySof IOLs continuously increased for up to 15 years postoperatively and was a risk factor for decreased visual acuity. ${ }^{19}$ Beheregaray et al directly compared OSI in AcrySof lenses with subsurface nanoglistenings to a control group without glistenings (with much shorter follow-up of 0.59 years vs 6.48 years in the AcrySof group) and found significantly higher OSI in the eyes with nanoglistenings. ${ }^{5}$ They also reported that with the increase in forward light scattering, visual acuity and contrast sensitivity declined but remained within normal range.

In the current study, both groups had long-term follow-up ranging from 14 months to almost 10 years; the eyes implanted with Tecnis IOLs had longer follow-up than those implanted with AcrySof IOLs ( $P$-value $=0.054)$. Despite this, the eyes implanted with Tecnis IOLs showed better longterm optical performance in terms of both OSI and visual acuity recorded under mesopic light conditions. Separately, there was a significant age difference of $\sim 3$ years between the patients in the AcrySof group and those in the Tecnis group. Since there is no association between glistenings and patient age, this difference is unlikely to have contributed to the differences in optical performance.

OSI measurements could be affected by factors other than glistenings in the lens optics. However, other common sources of light scatter, including poor tear film, uncorrected refractive error, or excessive higher order aberrations and PCO or other ocular media opacities ${ }^{7-9}$ have been ruled out through the inclusion/exclusion criteria of the study.

Previous studies have reported that glistenings are associated with glaucoma. ${ }^{20}$ This may be due in part to chronic use of antiglaucoma topical medications used to lower IOP. Active ingredients or preservatives in glaucoma medications may either directly or indirectly affect the composition of aqueous humor, thereby inducing glistenings. ${ }^{21,22}$ Schweitzer et al have also reported that the incidence and severity of glistenings in glaucomatous eyes were significantly associated with the number of topical antiglaucoma medications instilled daily. ${ }^{23}$

In the current study, there were statistically significantly more patients affected by glaucoma in the AcrySof group. It was considered that this could make the AcrySof group more susceptible to glistening formation and increased light scatter. In order to eliminate this potential source bias, results for non-glaucomatous eyes were analyzed, in addition to those for all eyes. In the subgroup analysis of non-glaucomatous eyes, mean mesopic CDVA and OSI were better in the Tecnis group ( $P=0.135$ and $P=0.028$, respectively), with results essentially similar to those observed for all eyes.

\section{Conclusion}

The use of double-pass wavefront (OQAS) technology to measure visual quality is very promising, both for screening preoperative patients and for evaluating visual quality over time. It is important to note that the preliminary results of this pilot study limit drawing definite conclusions and future larger studies will be required to confirm these findings and to establish a definitive trend. Studies with a larger sample size (n) are more likely to improve the statistical significance ( $P$-values) observed in the current study. A larger study in which OSI and CDVA are evaluated in two or more IOL groups over the same series of postoperative visits (1 month, 1 year, and 5 years, for example) and correlated with the presence of glistenings at each visit would be very helpful in furthering our understanding of the factors affecting visual quality over time, albeit difficult to conduct. The role of OSI in understanding and comparing intraocular lenses and lens materials should continue to be explored. 


\section{Acknowledgments}

The author wishes to thank Jan Beiting (Wordsmith Consulting, Cary, NC, USA) and Raman Bedi, MD (IrisARC Analytics, Research \& Consulting, Chandigarh, India) for research, statistics, and editorial assistance in the preparation of this manuscript. Funding for their assistance was provided by Abbott Medical Optics, Inc. This study was presented at the American Society of Cataract and Refractive Surgery Annual Meeting, New Orleans, LA, USA, during May 2016.

\section{Disclosure}

GHH Beiko is a consultant to AMO, B\&L, and is on the speakers' bureau for Ophtec. The authors report no other conflicts of interest in this work.

\section{References}

1. Castillo-Gómez A, Carmona-González D, Martínez-de-la-Casa JM, Palomino-Bautista C, García-Feijoo J. Evaluation of image quality after implantation of 2 diffractive multifocal intraocular lens models. J Cataract Refract Surg. 2009;35(7):1244-1250.

2. Lee H, Lee K, Ahn JM, Kim EK, Sgrignoli B, Kim TI. Double-pass system assessing the optical quality of pseudophakic eyes. Optom Vis Sci. 2014;91(4):437-443.

3. Lee H, Lee K, Ahn JM, Kim EK, Sgrignoli B, Kim TI. Evaluation of optical quality parameters and ocular aberrations in multifocal intraocular lens implanted eyes. Yonsei Med J. 2014;55(5):1413-1420.

4. de Waard PW, IJspeert JK, van den Berg TJ, de Jong PT. Intraocular light scattering in age-related cataracts. Invest Ophthalmol Vis Sci. 1992; 33(3):618-625.

5. Beheregaray S, Yamamoto T, Hiraoka T, Oshika T. Influence on visual function of forward light scattering associated with subsurface nanoglistenings in intraocular lenses. J Cataract Refract Surg. 2014;40(7): 1147-1154.

6. Martinez-Roda JA, Vilaseca M, Ondategui JC, et al. Optical quality and intraocular scattering in a healthy young population. Clin Exp Optom. 2011;94(2):223-229.

7. Kobashi H, Kamiya K, Yanome K, Igarashi A, Shimizu K. Longitudinal assessment of optical quality and intraocular scattering using the doublepass instrument in normal eyes and eyes with short tear breakup time. PLoS One. 2013;8(12):e82427.

8. Tutt R, Bradley A, Begley C, Thibos LN. Optical and visual impact of tear break-up in human eyes. Invest Ophthalmol Vis Sci. 2000;41(13): 4117-4123.
9. Beiko GH. A pilot study to determine if intraocular lens choice at the time of cataract surgery has an impact on patient-reported driving habits. Clin Ophthalmol. 2015;9:1573-1579.

10. Nanavaty MA, Spalton DJ, Boyce JF. Influence of different acrylic intraocular lens materials on optical quality of vision in pseudophakic eyes. J Cataract Refract Surg. 2011;37(7):1230-1238.

11. Lim SA, Hwang J, Hwang KY, Chung SH. Objective assessment of nuclear cataract: comparison of double-pass and Scheimpflug systems. $J$ Cataract Refract Surg. 2014;40(5):716-721.

12. Artal P, Benito A, Pérez GM, et al. An objective scatter index based on double-pass retinal images of a point source to classify cataracts. PLoS One. 2011;6(2):e16823.

13. Colin J, Praud D, Touboul D, Schweitzer C. Incidence of glistenings with the latest generation of yellow-tinted hydrophobic acrylic intraocular lenses. J Cataract Refract Surg. 2012;38(7):1140-1146.

14. Leydolt C, Schriefl S, Stifter E, Haszcz A, Menapace R. Posterior capsule opacification with the iMics 1 NY-60 and AcrySof SN60WF 1-piece hydrophobic acrylic intraocular lenses: 3 -year results of a randomized trial. Am J Ophthalmol. 2013;156(2):375-381.e2.

15. Behndig A, Mönestam E. Quantification of glistenings in intraocular lenses using Scheimpflug photography. J Cataract Refract Surg. 2009; 35(1):14-17.

16. Johansson B. Posterior capsule opacification development and glistenings in 2 hydrophobic acrylic 1-piece IOLs: 3-year follow-up intraindividual comparison. Poster presented at: 2015 ASCRS ASOA Symposium and Congress; April 18; 2015; San Diego, CA.

17. van der Mooren M, Franssen L, Piers P. Effects of glistenings in intraocular lenses. Biomed Opt Express. 2013;4(8):1294-1304.

18. Nagata M, Matsushima H, Mukai K, et al. Clinical evaluation of the transparency of hydrophobic acrylic intraocular lens optics. J Cataract Refract Surg. 2010;36(12):2056-2060.

19. Miyata K, Honbo M, Otani S, Nejima R, Minami K. Effect on visual acuity of increased surface light scattering in intraocular lenses. J Cataract Refract Surg. 2012;38(2):221-226.

20. Colin J, Orignac I, Touboul D. Glistenings in a large series of hydrophobic acrylic intraocular lenses. J Cataract Refract Surg. 2009; 35(12):2121-2126.

21. Ayaki M, Nishihara H, Yaguchi S, Koide R. Surfactant induced glistenings: surface active ingredients in ophthalmic solutions may enhance water entry into the voids of implanted acrylic intraocular lenses. J Long Term Eff Med Implants. 2006;16(6):451-457.

22. Ayaki M, Nishihara H, Yaguchi S, Koide R. Effect of ophthalmic solution components on acrylic intraocular lenses. J Cataract Refract Surg. 2007;33(1):122-126.

23. Schweitzer C, Orignac I, Praud D, Chatoux O, Colin J. Glistening in glaucomatous eyes: visual performances and risk factors. Acta Ophthalmol. 2014;92(6):529-534.

\section{Clinical Ophthalmology}

\section{Publish your work in this journal}

Clinical Ophthalmology is an international, peer-reviewed journal covering all subspecialties within ophthalmology. Key topics include: Optometry; Visual science; Pharmacology and drug therapy in eye diseases; Basic Sciences; Primary and Secondary eye care; Patient Safety and Quality of Care Improvements. This journal is indexed on Submit your manuscript here: http://www.dovepress.com/clinical-ophthalmology-journal

\section{Dovepress}

PubMed Central and CAS, and is the official journal of The Society of Clinical Ophthalmology (SCO). The manuscript management system is completely online and includes a very quick and fair peer-review system, which is all easy to use. Visit http://www.dovepress.com/ testimonials.php to read real quotes from published authors. 